\title{
Management of end-stage sarcoidosis: pulmonary hypertension and lung transplantation
}

\author{
Oksana A. Shlobin and Steven D. Nathan
}

ABSTRACT: Sarcoidosis is not only a multisystem, but also a multinational disease that is prevalent throughout the world, including Europe, the USA and Japan. Lung involvement in sarcoidosis is seemingly invariable, with up to $95 \%$ of patients manifesting some form of pulmonary disease during the course of their lifetime. The natural history of sarcoidosis in the lung is quite variable and spans the spectrum from spontaneous resolution to advanced fibrocystic disease in $\sim 5 \%$ of cases. Advanced sarcoidosis will be the subject of this review with a special focus on pulmonary hypertension and lung transplantation as a last-resort treatment option for some patients with end-stage disease.

\section{KEYWORDS: Lung transplantation, pulmonary hypertension, sarcoidosis}

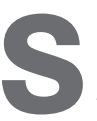
arcoidosis is not only a multisystem, but also a multinational disease that is prevalent throughout the world including Europe, the USA and Japan [1, 2]. In Europe, especially in the Scandinavian countries and Ireland, it affects the Caucasian population, while in the USA it tends to occur more commonly in African-Americans. It has a reported incidence in females of 21.6 and in males of 15.3 cases per 100,000 population per year [2].

Lung involvement in sarcoidosis is seemingly invariable, with up to $95 \%$ of patients manifesting some form of pulmonary disease during the course of their lifetime [1]. However, the natural history of sarcoidosis in the lung is quite variable and spans the spectrum from spontaneous resolution to advanced fibrocystic disease. Fortunately, in most cases, there is more of a propensity for the former and more benign clinical course. However, in about $5 \%$ of cases, permanent severe pulmonary dysfunction occurs, which accounts for most of the morbidity and mortality seen with the disease (fig. 1) [1]. Indeed, respiratory failure is the most common cause of death from sarcoidosis in the USA and Europe, as opposed to Japan, where cardiac sarcoidosis is the major cause of mortality [3]. Advanced sarcoidosis will be the subject of this review with a special focus on pulmonary hypertension and lung transplantation (LTx) as a last-resort treatment option for select patients with end-stage disease.

\section{PULMONARY HYPERTENSION \\ Overview}

Sarcoidosis is characterised pathologically by non-caseating granulomas and it is the sequelae of these that determine the clinical manifestations of the disease. Patients who progress to develop stage IV fibrocystic disease commonly manifest physiologically with varying degrees of restrictive and obstructive disease and a decreased diffusing capacity of the lung for carbon monoxide $(\mathrm{DL}, \mathrm{CO})[1]$. Pulmonary hypertension $(\mathrm{PH})$ is an increasingly recognised complication of sarcoidosis with a reported prevalence between 1 and $28 \%$ of all patients at rest and up to $43 \%$ with exercise [4-6]. PH most commonly occurs in association with advanced stage IV disease, but can also occur in the context of relatively normal lung function and preserved parenchymal architecture. Patients with recalcitrant dyspnoea and normal left ventricular function have a higher reported $\mathrm{PH}$ prevalence of $\sim 53 \%$ [7]. Sarcoidosis patients who are listed for LTx have an even higher rate of $\sim 74 \%$ [8]. In our own clinic (Inova Fairfax Hospital, Falls Church, VA, USA), we have found a similar prevalence of $\mathrm{PH}(\sim 75 \%)$

\section{AFFILIATIONS}

Advanced Lung Disease and Transplant Program, Dept of Medicine, Inova Fairfax Hospital, Falls Church, VA, USA.

\section{CORRESPONDENCE}

O.A. Shlobin

Advanced Lung Disease and

Transplant Program

Inova Fairfax Hospital

3300 Gallows Road

Falls Church

VA 22042

USA

E-mail: oksana.shlobin@inova.org

Received:

Oct 102011

Accepted after revision:

Dec 072011

First published online:

Jan 122012 


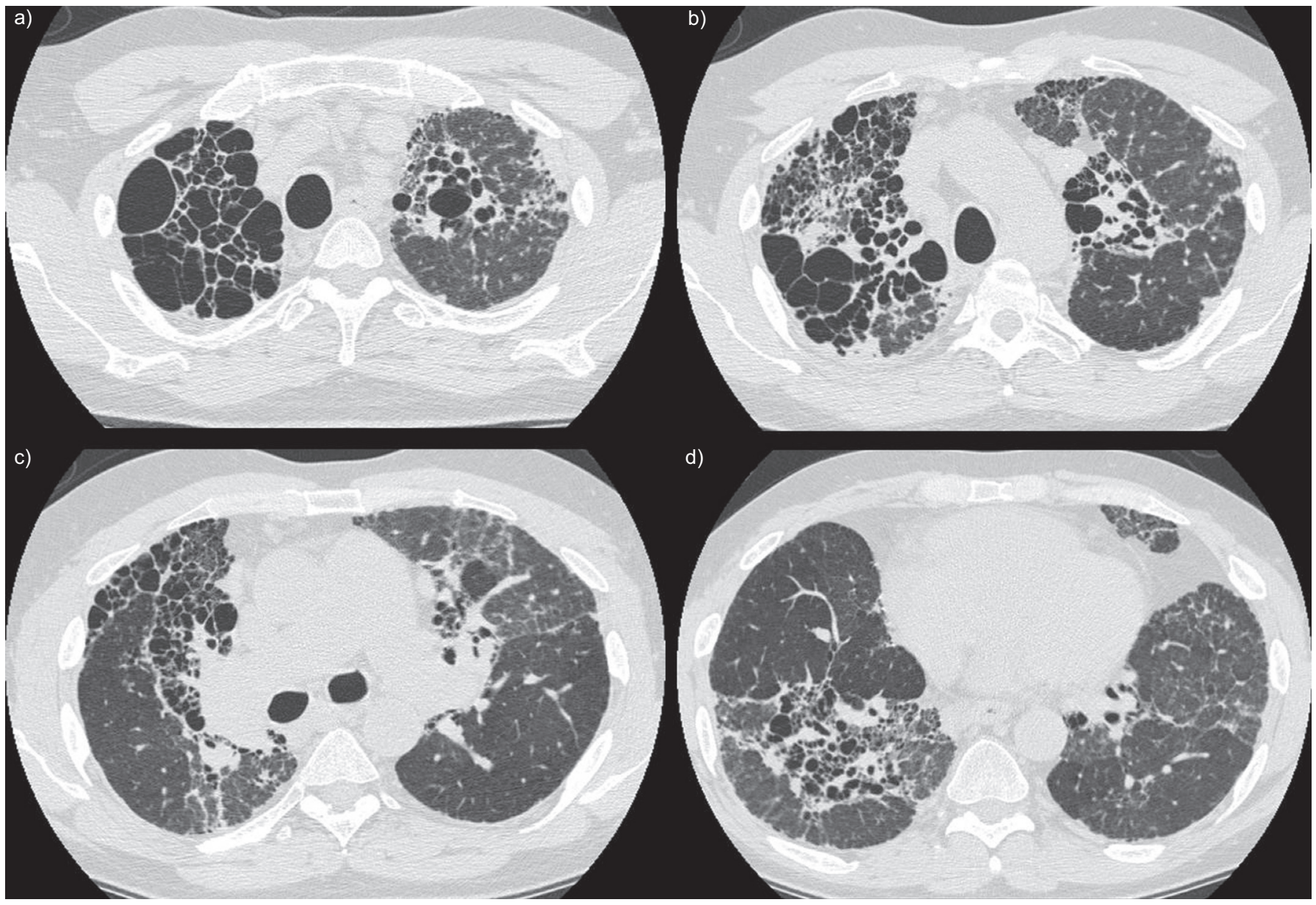

FIGURE 1. Computed tomography (CT) images. a-d) CT scan of the chest showing stage IV sarcoidosis with associated pulmonary hypertension (mean pulmonary arterial pressure $49 \mathrm{mmHg}$ ) and an enlarged pulmonary artery and fibrocystic sarcoidosis.

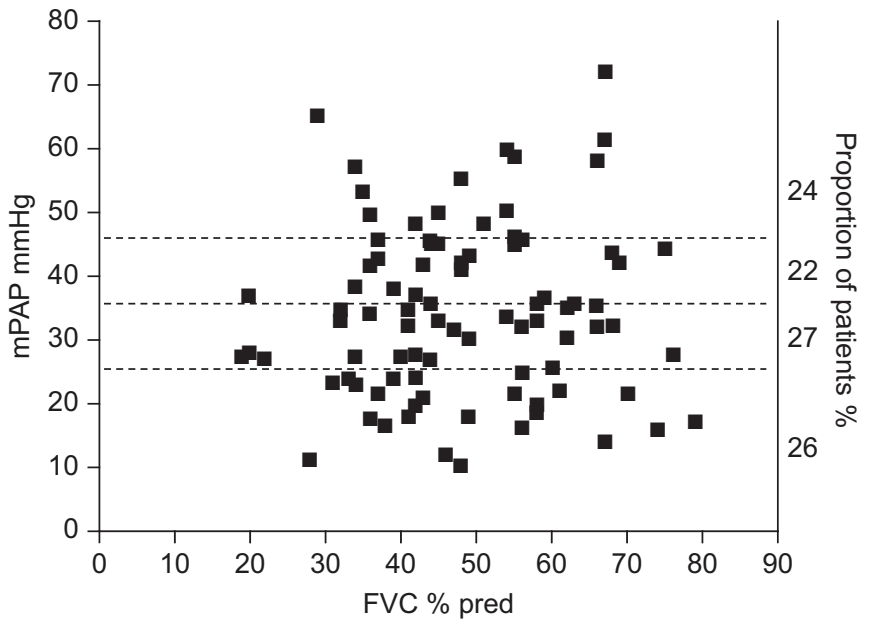

FIGURE 2. Distribution of mean pulmonary artery pressure (mPAP) in relation to the forced vital capacity (FVC) \% predicted (\% pred) in a cohort of 104 patients with sarcoidosis. The horizontal dashed lines and right y-axis stratify the patients by severity of pulmonary hypertension (data from Inova Fairfax Hospital, Falls Church, VA, USA). based on right heart catheterisation of 104 transplant and non-transplant candidates with advanced sarcoidosis evaluated over a 14-yr period (fig. 2).

\section{Pathophysiology of $\mathrm{PH}$ in sarcoidosis}

The most recent World Health Organization (WHO) conference (Dana Point, CA, USA, 2008) categorised PH into five groups. Group I or pulmonary arterial hypertension (PAH) includes the prototypical disease of idiopathic $\mathrm{PAH}$ and other forms of associated PAH, while group II is $\mathrm{PH}$ related to left-sided heart disease, group III is seen in association with lung disease, group IV is due to chronic thromboembolic disease and group $\mathrm{V}$ is comprised of miscellaneous conditions. Sarcoidosis is categorised in the last group, since the pathogenesis of associated $\mathrm{PH}$ is complex and multifactorial with characteristics of and similarities to all four former groups (fig. 3) [9, 10].

The majority of sarcoidosis patients with $\mathrm{PH}$ have stage IV disease and show associated impairment in pulmonary function tests (PFTs) (fig. 2) [11]. PH is, therefore, usually attributed to the destruction of the capillary bed by the fibrotic process and/ or regional hypoxaemic vasoconstriction. However, the severity 


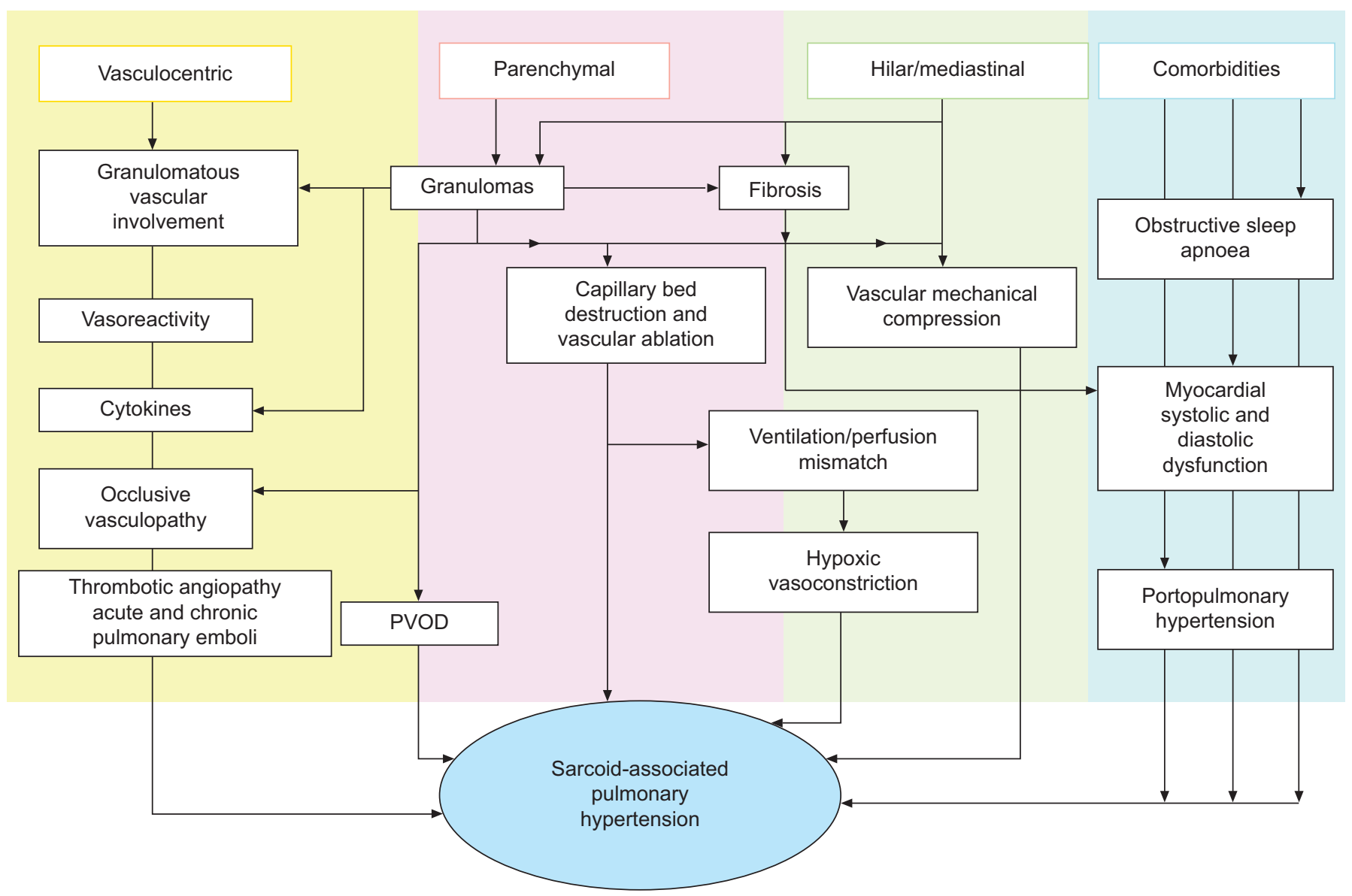

FIGURE 3. Schematic representation of the interplaying factors contributing to the pathogenesis of pulmonary hypertension in sarcoidosis. PVOD: pulmonary venoocclusive disease.

of PH does not always correlate with the degree of parenchymal lung disease and blood gas abnormalities, suggesting that other mechanisms may be playing a role (fig. 3 ) $[4,8,11]$. These other contributors may be directly related to the pulmonary vasculature or extrapulmonary factors, either within the mediastinum or in the form of an associated comorbidity.

Granulomatous involvement of the pulmonary vessels is common in sarcoidosis-associated $\mathrm{PH}$, and has been described in $69-100 \%$ of patients with $\mathrm{PH}$ [12]. The granulomatous inflammation tends to involve the lung in a lymphatic distribution, thus neighbouring the granulomas adjacent to the pulmonary arteries and veins in the bronchovascular bundles and interlobular septae. The granulomas may be found in all layers of the vessel wall, but other pathological findings are commonly seen, including inflammation, necrosis, destruction of the musculoelastic media of the small and medium-sized vessels, endothelial proliferation and disruption of the basal lamina. As a result, an occlusive vasculopathy may develop, especially in the small arterioles and venules [12, 13]. When the granulomatous infiltration involves the pulmonary veins preferentially, this may result in a clinical picture that mimics pulmonary veno-occlusive disease (PVOD) [14-16]. In addition, an intrinsic venopathy may result in a PVOD-like clinical picture [11]. In situ thrombosis (thrombotic angiopathy) is another intravascular mechanism, which has been described previously [13]. More proximally, mediastinal or hilar adenopathy and any accompanying fibrosis can result in mechanical extrinsic compression of the large pulmonary arteries and an increased pulmonary vascular resistance (figs 1 and 4) [11, 17-19].

The geographical distribution of the non-caseating granulomas and fibrosis differentiates the $\mathrm{PH}$ related to sarcoidosis from WHO group I PAH, which tends to involve the pulmonary vasculature in a more homogeneous fashion. Typically, the architectural distortion that results from fibrocavitary disease favours a more central and upper lobe distribution. Parenchymal remodelling may also result in vessel tortuosity, turbulent flow and shear stresses, which may perpetuate the development and progression of $\mathrm{PH}$ [20]. The heterogeneous distribution of disease might contribute to the apparent dissociation between the degree of restrictive physiology, a surrogate for the parenchymal disease burden, and the prevalence and severity of $\mathrm{PH}$. The central predilection specifically may involve the proximal lobar vessels with a greater propensity for the subsequent development of $\mathrm{PH}$. Fibrosis in proximity to the pulmonary arterial circulation may also adversely affect the vascular capacitance, a surrogate of vessel stiffness. A low vascular capacitance has been demonstrated to portend a worse prognosis in patients with $\mathrm{PAH}$ [21]. If the same holds true for the $\mathrm{PH}$ of sarcoidosis, this might help explain the significant mortality 


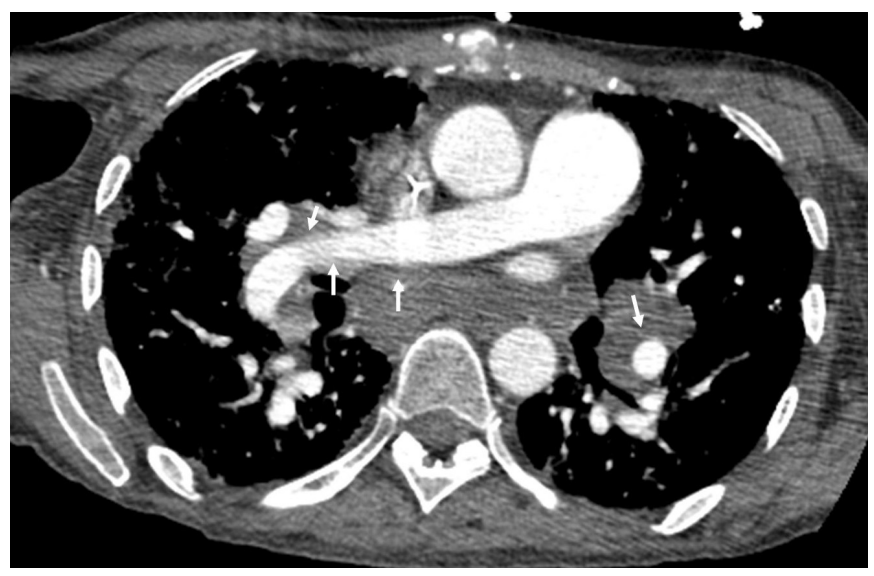

FIGURE 4. Contrast-enhanced computed tomography image of the chest of a sarcoidosis-pulmonary hypertension patient with lymphadenopathy (white arrows) surrounding the right pulmonary artery and left lower pulmonary artery.

implications of even mild elevations in pulmonary arterial pressures.

There are a number of cytokines that have been found to be upregulated in sarcoidosis that could perpetuate the development of PH. One such example is endothelin (ET)-1, which has been implicated in the pathogenesis of both idiopathic PAH and various interstitial lung diseases [22-24]. ET-1 is produced primarily by endothelial cells, smooth muscle and airway epithelial cells, with production induced by hypoxia, shear stress and various growth factors and cytokines [24]. It is a potent vasoconstrictor that is also thought to have long-term vascular remodelling properties [24]. Tumour necrosis factor (TNF)- $\alpha$, which is thought to play a central role in the pathogenesis of sarcoidosis, has also recently been implicated in the inflammatory pathway of PAH $[25,26]$. Conceptually, therefore, the up-regulation of these, and perhaps other cytokines, may contribute to the development of $\mathrm{PH}$. The prospect of cytokine cross-talk may, therefore, provide an additional explanation for the disproportionate $\mathrm{PH}$ that is seen in the context of well-preserved lung volumes.

There also may be increased pulmonary vasoreactivity in sarcoidosis, as suggested by the favourable acute response to vasodilators, including nitric oxide (NO) and prostacyclin. The mechanism for this is not clear, but may be partially explained by endothelial damage from sarcoidosis granulomas, with a subsequent decrease in synthesis and release of $\mathrm{NO}$ and prostaglandins. This may have long-term sequelae with chronic, pulmonary vasoconstriction and associated remodelling $[27,28]$.

In some cases, extrapulmonary manifestations of sarcoidosis may also contribute to the development of PH. Not infrequently, direct myocardial involvement by granulomas and myocardial fibrosis may lead to left ventricular systolic and diastolic dysfunction [29]. In one study, 30\% of sarcoidosis patients with evidence of $\mathrm{PH}$ demonstrated elevated pulmonary capillary wedge pressures $(P \mathrm{pcw})$. This underscores the need to rule out left-sided heart disease in the comprehensive evaluation of $\mathrm{PH}$ related to sarcoidosis [30]. As with all forms of $\mathrm{PH}$, right heart catheterisation is, therefore, mandatory in establishing the diagnosis.
Hepatic granulomatous infiltration and subsequent cirrhosis may be seen as a complication of the disease, and therefore portopulmonary hypertension should be considered in patients with stigmata of liver dysfunction [31]. Other common comorbidities, which are not necessarily sarcoidosis-specific, including obstructive sleep apnoea (OSA), should not be overlooked if patients are thus predisposed. Indeed, the prevalence of OSA in sarcoidosis has been reported to be $17 \%$, which is much higher than what might be expected in a healthy patient population [32]. Finally, while chronic thromboembolic disease should be considered as a potential cause of or contributor to $\mathrm{PH}$, acute pulmonary embolism might also warrant exclusion in the context of new acute or subacute shortness of breaths and/or signs of increasing right-sided heart failure $[33,34]$.

\section{Impact and outcomes of $\mathrm{PH}$ in sarcoidosis}

The presence of $\mathrm{PH}$ has been shown to be associated with greater supplemental oxygen requirements, reduced functional capacity and greater caregiver dependency [35]. The mortality implications of any $\mathrm{PH}$, both precapillary and venous, in the context of sarcoidosis are also profound, with a $>10$-fold increase in mortality and an estimated 5-yr survival of only $59 \%[11,30]$. Sarcoidosis PH patients are more likely to be listed for LTx and, not surprisingly, also have a greater likelihood of succumbing while on the waiting list $[8,36]$. One of the issues in sarcoidosis, as with all forms of parenchymal lung disease associated $\mathrm{PH}$, is whether patients are succumbing because of $\mathrm{PH}$ or in the presence of $\mathrm{PH}$. With regards to the latter scenario, it might be that $\mathrm{PH}$ is a surrogate for another disease-related process that is driving mortality. In one study, which demonstrated that $\mathrm{PH}$ was associated with sarcoidosis mortality, the only haemodynamic factor that remained predictive of mortality after multivariable analysis was the right arterial pressure (Pra) [36]. Moreover, this study also demonstrated haemodynamic progression of $\mathrm{PH}$ in the patient cohort. This evidence of right-sided heart failure infers that patients with sarcoidosis-related $\mathrm{PH}$ are indeed dying from their $\mathrm{PH}$, rather than the $\mathrm{PH}$ being an epiphenomenon.

\section{Clinical presentation and diagnostic testing}

The diagnosis of $\mathrm{PH}$ in sarcoidosis can be difficult, as the most common symptom is dyspnoea on exertion, which is frequently attributed to the underlying parenchymal lung disease [37]. One study reported no difference in the presenting symptoms of sarcoidosis patients with or without concomitant $\mathrm{PH}$ [4]. PH should be suspected in any patient with signs and symptoms of right-sided congestive heart failure, especially lower-extremity oedema. However, the clinical signs of rightsided heart failure have a low sensitivity, manifesting in as few as $21 \%$ of patients with $\mathrm{PH}$ [4]. Therefore, a high index of suspicion needs to be maintained, especially in patients with symptoms that appear to be out of proportion to the degree of parenchymal lung disease, or who have more subtle signs of PH including a loud or palpable $\mathrm{P}_{2}$ heart sound.

Although $\mathrm{PH}$ is more common in patients with advanced fibrosis, there are no specific radiographic findings that predict the presence or absence of $\mathrm{PH}[5,11]$. Chest radiography frequently shows evidence of hilar adenopathy; however, hilar fullness may also be due to pulmonary artery enlargement. 
In this regard, computed tomography (CT) of the chest can be very helpful in providing the structural detail necessary to discern these. The presence of large pulmonary arterial segments on CT should raise the suspicion for underlying $\mathrm{PH}$, although the predictive accuracy of this finding does require further study. There are additional CT findings that should raise the suspicion for $\mathrm{PH}$ including evidence of extrinsic compression of large pulmonary arteries by lymphadenopathy or fibrosis (fig. 4).

Blood tests that have been shown to correlate with the presence or severity of PAH include brain natriuretic peptide (BNP) and N-terminal fragment-proBNP (NT-proBNP) levels. There are data to suggest that an elevated BNP is a marker of a poor prognosis in patients with chronic lung diseases [38]. In one study of patients with interstitial lung disease, an elevated BNP was the strongest predictor of overall mortality, independent of the severity of the underlying fibrosis [39]. However, the BNP might be a global biomarker of cardiac dysfunction, rather than being specific for PH. Indeed, in a recently published echocardiography-based prospective study of 150 Japanese patients with sarcoidosis, NT-proBNP was found to be a useful biomarker in identifying cardiac sarcoidosis, but not PH [40].

Pulmonary function data may provide helpful information. Specifically, there is some indication that the lower the $D \mathrm{~L}, \mathrm{CO}$, the greater the likelihood of underlying PH. A DL,CO $<60 \%$ predicted has been reported to be associated with a seven-fold increase in underlying $\mathrm{PH}$ [41]. Although sarcoidosis $\mathrm{PH}$ patients tend to have more restrictive disease, the correlation between $\mathrm{PH}$ and measures of lung volumes is poor, since $\mathrm{PH}$ can develop at any stage of the underlying disease (fig. 2).

Sarcoidosis $\mathrm{PH}$ patients have greater supplemental oxygen needs, shorter 6-min walking test (6MWT) distances and lower arterial oxygen saturation measured by pulse oximetry $\left(\mathrm{Sp}_{\mathrm{p}} \mathrm{O}_{2}\right)$ with exercise $[4,8]$. Patients who desaturate to $<90 \%$ are $12-$ fold more likely to have associated $\mathrm{PH}[41,42]$. Conversely, the absence of desaturation to $<90 \%$ with exercise implies a low likelihood of significant $\mathrm{PH}[41,42]$. The association of $\mathrm{PH}$ with a lower $\mathrm{Sp}_{\mathrm{p}} \mathrm{O}_{2}$ raises the pathophysiological conundrum of whether the $\mathrm{PH}$ is causing the desaturation or if hypoxaemia is perpetuating the $\mathrm{PH}$. It is likely that both scenarios are true with each pathological element perpetuating the other. Indeed, the temporal nature of the pathophysiological sequence is semantic, since neither scenario diminishes the utility of the $6 \mathrm{MWT}$ as a screening tool for PH. Also, any hypoxaemia should warrant the institution of supplemental oxygen, especially in the presence of documented $\mathrm{PH}$ [42]. The multisystem nature of sarcoidosis invokes other possible reasons for a shorter distance. It is possible, therefore, that the distance component is more useful to evaluate response to therapy, rather than as a screening tool for $\mathrm{PH}$ [41-43]. In an attempt to account for both the distance and $\mathrm{Sp}, \mathrm{O}_{2}$ components of the $6 \mathrm{MWT}$, the composite distance saturation product (DSP) has been examined in sarcoidosis and indeed, a lower DSP has been demonstrated to be associated with echocardiographydiagnosed PH [44].

Continuous Doppler flow transthoracic echocardiogram (TTE) is the most reliable noninvasive test to screen for the presence of PH. TTE allows calculation of the right ventricular systolic pressures (RVSP) from the maximal velocity of the tricuspid regurgitation jet and an estimation of the Pra. However, there are inherent variables that can affect the accuracy of this calculation, which may be further compromised in the presence of chronic lung diseases [45]. Specifically, in a study of 374 subjects with various forms of advanced lung disease including sarcoidosis, the RVSP could only be estimated in $44 \%$ of the patients. Additionally, in approximately half of these cases, pressure estimations were inaccurate when compared with right heart catheterisation-derived numbers. TTE tends to overestimate, but can also underestimate, the true RVSP and, therefore, does not have sufficient predictive properties to be solely relied upon to diagnose or rule out $\mathrm{PH}$ [45]. However, TTE is very useful in assessing for other cardiac abnormalities, such as left ventricular systolic or diastolic dysfunction, valvular abnormalities, the presence of shunts and pericardial effusions [43]. In the absence of tricuspid regurgitation, the diagnosis of $\mathrm{PH}$ should still be suspected when there are signs of right ventricular dysfunction, including dilatation, hypertrophy, systolic dysfunction and flattening or bowing of the interventricular septum [43]. The presence of any of these or other clinical features suspicious for the presence of $\mathrm{PH}$ should prompt right heart catheterisation to further characterise the pulmonary haemodynamics [37].

As with all forms of $\mathrm{PH}$, right heart catheterisation remains the gold standard for the diagnosis of $\mathrm{PH}$ in sarcoidosis. In addition to allowing the direct measurement of the pulmonary artery pressures, the Pra and cardiac output are also obtained, all of which impart additional important prognostic information $[35,36]$. Measurement of the $P$ pcw is also essential in differentiating between arterial and venous pulmonary hypertension. There are no guidelines as to when a right heart catheterisation should be obtained in patients with sarcoidosis. This should be evaluated on a case-by-case basis taking into account the patients' clinical presentation, which might include their symptoms, clinical signs, echocardiography findings, $6 \mathrm{MWT}$ distance, PFT data or BNP. The decision to proceed with right heart catheterisation should also be predicated on whether this will impact the patients' management. For example, the haemodynamic variables might provide important prognostic data including informing the decision about the timing of LTx. Also, if there is a strong likelihood that the $\mathrm{PH}$ will be deemed sufficiently severe to warrant therapy, then this might provide reason to proceed with right heart catheterisation.

\section{Management of $\mathrm{PH}$ in sarcoidosis}

The optimal management approach to $\mathrm{PH}$ associated with sarcoidosis is unknown and is based on limited evidence. Modifiable risk factors and comorbidities should be sought and treated where indicated. Hypoxaemia correlates to some extent with the severity of $\mathrm{PH}$, and supplemental oxygen is thus recommended to reverse resting hypoxaemia. The presence of any contributory comorbidities, including OSA, cardiac dysfunction or thromboembolic disease, warrants standard therapeutic interventions [13]. The treatment of sarcoidosis with anti-inflammatory and other immunomodulating therapies has a theoretic role if the predominant 
pathological potentiator of the $\mathrm{PH}$ is active sarcoidosis. However, such an approach has not demonstrated consistent benefits, with response rates of only $20-30 \%$ reported in small series [11, 46-48]. However, in no studies have patients with stage IV disease, the most common stage associated with $\mathrm{PH}$, shown a significant haemodynamic response to corticosteroids. Thus, steroids should be avoided in patients with evidence of advanced fibrocystic disease and ought to be considered only for patients with evidence of active disease and/or compression of central vascular structures by bulky lymphadenopathy $[47,48]$.

The use of currently available pulmonary vasoactive agents is controversial since there have been no randomised, placebocontrolled studies to demonstrate their efficacy in sarcoidosis patients. When therapy is being considered, the term "disproportionate $\mathrm{PH}^{\prime \prime}$ is frequently used, with the inference being that there is a component of the pressure increase that is not explained by, or directly due to, the extent of the parenchymal lung disease. This is a concept that is frequently spoken of in the context of not only sarcoidosis, but many other forms of diffuse parenchymal lung diseases. However, there are no studies attempting to address what constitutes disproportionate $\mathrm{PH}$, and it is likely that it cannot be defined by a single pressure cut-point. An alternative concept or methodology to address this is to regard $\mathrm{PH}$ as disproportionate if when treated, it results in a measurable clinical improvement.

When therapy is being considered, it is important to bear in mind the potential to do more harm than good in patients with significant parenchymal lung disease. Specifically, any pulmonary vasodilatation may potentiate ventilation/perfusion mismatching with worsening hypoxaemia, while it is also possible that a pulmonary oedema pattern might be precipitated in those patients with pre-existing PVOD-like lesions [19, $43,49]$. Despite these caveats, there are a number of small case series attesting to the potential utility of $\mathrm{PAH}$-specific therapies in patients with sarcoidosis (table 1). The current available approved therapies for $\mathrm{PAH}$ target one of three pathways, which include the ET, NO and prostacyclin pathways.

\section{The ET pathway}

The finding of increased ET-1 levels in patients with sarcoidosis and in subjects with idiopathic PAH provides a theoretical rationale for the use of endothelin receptor antagonists (ERAs). However, experience in sarcoidosis is mostly limited to a few retrospective case series, where ERAs have been used alone or in combination with other medications. BAUGHMAN et al. [30] reported five patients in whom there was a decrease in the mean pulmonary artery pressure (mPAP) from an average of 50 to $35 \mathrm{mmHg}$ after $\geqslant 4$ months of treatment. Another study described seven patients treated either with bosentan alone $(n=3)$ or in combination with prostanoids $(n=4)$, in whom $\sim 50 \%$ responded to therapy after 6-18 months of follow-up [54]. A two-centre retrospective study by BARNETT et al. [52] reported outcomes in 22 sarcoidosis patients with $\mathrm{PH}$ who received a variety of vasoactive therapies, including bosentan $(n=12)$ and sildenafil $(n=9)$. An overall improvement in mPAP, pulmonary vascular resistance (PVR) and 6MWT distance was demonstrated, especially in those patients with limited fibrosis. Despite this apparent salutary response, the overall prognosis remained quite poor, with a 3-yr survival of only $74 \%$. There has been one randomised, placebo-controlled study of ambrisentan, a selective ET receptor A blocker, in 17 patients with sarcoidosisrelated $\mathrm{PH}$. Unfortunately this was a negative study that has only been reported in abstract form thus far [55]. A large prospective randomised 16-week study of bosentan in this patient population is currently underway, with an anticipated completion date of December 2012 [56].

\section{NO and phosphodiesterase inhibitors}

$\mathrm{NO}$ is a potent vasodilator with a very short half-life that may be delivered via the inhaled route. There has been one report describing the use of ambulatory inhaled NO in eight patients with sarcoidosis, of whom five had improvements in their $6 \mathrm{MWT}$ distance [27]. This is not, as yet, a feasible therapeutic option due to the lack of approved and available ambulatory delivery systems. The NO pathway may be targeted by selective phosphodiesterase type-5 (PDE-5) inhibitors. This blockade increases local NO levels in the arterial smooth muscle cells, thereby promoting short- and long-term vasodilation and, possibly, long-term anti-proliferation of vascular smooth muscle cells [19, 49]. Aside from the nine patients reported in the article by BARNETT et al. [52], there has been one additional retrospective study of 12 patients who were treated with sildenafil for a range of 1-12 months [53]. Although there was no significant change in the 6MWT distance, the study did demonstrate an improvement in the pulmonary haemodynamic profile with a reduction in the mPAP and PVR accompanied by an increase in the cardiac index. Although these findings are encouraging, the ultimate role of PDE-5 inhibitors in sarcoidosis-related $\mathrm{PH}$ remains to be determined by further prospective studies.

\section{The prostacyclin pathway}

This pathway is targeted by prostanoid analogues that may be administered intravenously, subcutaneously or via the inhaled route. These agents are potent vasodilators that may also inhibit platelet aggregation [19, 26, 49]. There are very limited data on the use of intravenous epoprostenol in sarcoidosis, but in one study of six patients with advanced fibrotic disease, there was an improvement in functional class in all but one of the patients [51]. Improvements in functional class and pulmonary haemodynamics have also been demonstrated in another study that included the use of either inhaled NO or both inhaled NO and epoprostenol [27]. An open-label study of inhaled iloprost in 22 cases of sarcoidosis-related $\mathrm{PH}$ demonstrated haemodynamic improvement in six patients, with a $>20 \%$ decrease in the PVR [50]. Additionally, there were downstream clinical correlates noted, with an overall increase in the 6MWT distance $(\sim 30 \mathrm{~m})$ and improvements in patients' quality of life.

\section{Conclusion}

The cumulative evidence from the growing body of literature suggests a potential benefit of PAH-specific agents in some patients with sarcoidosis-associated $\mathrm{PH}$. However, before these therapies can be universally endorsed and adopted, it is necessary for the appropriate prospective, randomised, double-blind clinical trials to be undertaken and completed. Such studies are mandatory to validate that this therapeutic approach is of benefit and to best define the patient 
TABLE 1 Summary of currently available studies on treatment of sarcoidosis-associated pulmonary hypertension

\begin{tabular}{|c|c|c|c|}
\hline First author [ref.] & Study type (number treated) & Therapy (number treated) & Outcomes \\
\hline Preston [27] & Prospective observational (8) & $\begin{array}{l}\text { Inhaled NO (5), inhaled NO with i.v. EPO (1), } \\
\text { CCBs (2) }\end{array}$ & $\begin{array}{l}\text { Short-term } 20 \% \text { decrease in PVR and mPAP; } \\
\text { long-term increase in } 6 \mathrm{MWT}\end{array}$ \\
\hline BAUGHMAN [50] & Prospective open label 16 weeks (22) & Inhaled iloprost (15) & $\begin{array}{l}6 \text { out of } 15 \text { patients showed a decrease in mPAP/ } \\
\text { PVR, } 3 \text { out of } 15 \text { showed improvement in } 6 \mathrm{MWT}\end{array}$ \\
\hline FISHER [51] & Retrospective case series (7) & i.v. EPO (6), s.c. treprostinil (1) & Improved NYHA class \\
\hline MILMAN [53] & Retrospective chart review (12) & Sildenafil (12) & $\begin{array}{l}\text { Decrease in mPAP/PVR, increase in cardiac } \\
\text { output, no change in } 6 \mathrm{MWT}\end{array}$ \\
\hline Culver [54] & Retrospective chart review (7) & Bosentan (3), bosentan and i.v. EPO (4) & $\begin{array}{l}\text { Reduction in mPAP at } 6-18 \text { months in half } \\
\text { of the patients }\end{array}$ \\
\hline BAUGHMAN [30] & Retrospective chart review (5) & Bosentan (5) & $\begin{array}{l}\text { Reduction in mPAP from } 50 \mathrm{mmHg} \text { to } 35 \mathrm{mmHg} \\
\text { in } 3 \text { out of } 5 \text { patients at } 4 \text { months }\end{array}$ \\
\hline
\end{tabular}

NO: nitric oxide; i.v.: intravenous; EPO: epoprostenol; CCB: calcium channel blocker; PVR: pulmonary vascular resistance; mPAP: mean pulmonary artery pressure; 6MWT: 6-min walking test; NYHA: New York Heart Association; s.c.: subcutaneous.

phenotypes most likely to respond and least likely to deteriorate. In the absence of such trials, if any such therapy is contemplated, it should be implemented with caution and with the full knowledge and "buy in" of the patient. Each case should be treated as an "n=1" study with close serial follow-up. Monitoring of patients should include an assessment of their symptoms, the impact on their quality of life and an objective functional study, such as the 6MWT. Consideration should be given to discontinuing the medication in the absence of any improvement or in the presence of any untoward side-effects.

\section{THE ROLE OF LTX}

\section{Overview}

LTx has evolved into an important therapeutic option for many patients with various forms of advanced lung disease, including sarcoidosis. Based on data from the International Society of Heart and Lung Transplant (ISHLT), sarcoidosis represents $2.6 \%$ of all conditions for which transplants have been performed, compared with $31 \%$ for idiopathic pulmonary fibrosis (IPF), the most commonly transplanted fibrotic disorder [57]. Although sarcoidosis is a more common condition, fewer patients will advance to stage IV disease and therefore require transplant consideration. However, IPF is a disease of the elderly with more patients being disqualified by virtue of their age. National statistics from the USA of admissions and deaths based on International Classification of Diseases, Ninth Edition codes from 2009 provide a snapshot view of patients with either "IPF" or "sarcoidosis" of sufficient severity to warrant hospital admission. There were 3,289 IPF admissions (approximately one-third were $<64$ yrs of age), whereas there were 7,034 hospital admissions for sarcoidosis $(\sim 85 \%<64$ yrs of age). As a surrogate of disease severity, there were 478 IPF deaths versus 83 sarcoidosis-related deaths from among these patients. Thus, for every 5.75 in-hospital IPF deaths, there was one sarcoidosis mortality event. However, the IPF to sarcoidosis transplant ratio is double that, at $\sim 12: 1$. Comparison of these ratios, albeit accompanied by many caveats, does provide a foundation whereupon one might speculate about a relative under-representation of patients with sarcoidosis receiving lung transplants.

LTx carries with it significant risk of both morbidity and mortality and, therefore, as for all diseases, should only be considered for patients who have failed all other therapeutic modalities. In the context of sarcoidosis, transplantation is reserved for those patients with advanced fibrocystic disease in whom there is no possibility of spontaneous resolution and who have previously failed medical therapy. While it is hoped that transplantation will result in an improved quality of life, conceptually, the timing of the procedure is mostly determined by when it is deemed to confer a survival advantage.

There are very few studies that have examined the factors that predict the development of end-stage pulmonary disease in sarcoidosis. In the largest non-transplant cohort of 479 sarcoidosis patients followed $\leqslant 7$ yrs, the factors influencing the development of respiratory failure included both radiographic findings of fibrosis and a vital capacity $<2.5 \mathrm{~L}$. A vital capacity of $<1.5 \mathrm{~L}$ was present in all patients who subsequently developed end-stage disease [58]. The ISHLT listing guidelines are primarily based on studies examining the United Network of Organ Sharing (UNOS) database as well as a much smaller study of 43 patients from a single transplant centre [33, 36, 59]. Univariate analysis from this latter study demonstrated that resting hypoxaemia, $\mathrm{PH}(\mathrm{mPAP} \geqslant 35 \mathrm{mmHg})$, cardiac index $\leqslant 2 \mathrm{~L} \cdot \mathrm{min}^{-1} \cdot \mathrm{m}^{-2}$ and $P$ ra $\geqslant 15 \mathrm{mmHg}$ were all significantly associated with increased mortality on the waiting list. However, multivariate analysis identified only the $P$ ra $\geqslant 15 \mathrm{mmHg}$ as an independent prognostic variable, with a 5.2-fold increased risk of death [36].

The study that examined the UNOS database compared 427 sarcoidosis patients with 2,115 IPF patients, and found that 
mPAP was significantly higher in the sarcoidosis group [59]. The authors went on to develop a mortality prediction model that confirmed that $\mathrm{PH}$ played a prominent role in determining outcomes. Specifically, transplant list survivors had a mean \pm SD mPAP of $31.7 \pm 11.5$ compared with $41.1 \pm 14.4 \mathrm{mmHg}$ for those on the list who succumbed [35]. Differences in $\mathrm{PH}$ were not attributable to primary cardiac dysfunction, as the $P$ pcw was similar in the two groups. Other prognostic factors that were determined from this study included African-American race (OR 2.5) and the amount of supplemental oxygen used at rest $\left(2.2 \pm 2.0\right.$ versus $\left.2.9 \pm 1.7 \mathrm{~L} \cdot \mathrm{min}^{-1}\right)$.

The ISHLT consensus guidelines for the referral and selection of lung transplant recipients acknowledge the paucity of data and the difficulty in predicting outcomes for sarcoidosis [60]. Therefore, due to the unpredictable, variable and chronic nature of the disease, the optimal timing of listing and transplantation is difficult to discern. Nonetheless, when patients develop New York Heart Association class 3 and 4 symptoms, referral for transplant evaluation is recommended. Furthermore, the guidelines recommend that in concert with these symptoms, the presence of either hypoxaemia at rest, $\mathrm{PH}$ or a $P$ ra $\geqslant 15 \mathrm{mmHg}$ should prompt listing for transplantation.

Although these recommendations appear reasonable, they remain quite broad and often do not offer guidance to practitioners on dealing with individual patients. This lack of clarity might be responsible for the poor outcomes previously noted for listed sarcoidosis patients. In this regard, a singlecentre USA-based study in 2001 reported outcomes of listed sarcoidosis patients and demonstrated an astonishingly high mortality rate of 53\% [36]. A larger and broader-based cohort of patients drawn from the UNOS database was shown to have a waiting list mortality of $28 \%$, which is still unacceptably high [35]. This attrition was equivalent to that of IPF patients who were listed for LTx. The diagnosis of sarcoidosis is generally attained many years prior to patients' progression to advanced stage IV fibrocystic disease, as opposed to IPF patients, who are frequently diagnosed closer to the window of opportunity for transplantation. Therefore, this does raise the concern of whether the referral of sarcoidosis patients for transplant consideration might be unduly delayed.

These latter studies represent outcomes prior to the institution of the current USA lung allocation score (LAS), which was implemented in April 2005. Instead of the time-on-the list candidate ranking model, the LAS system utilises an organ allocation approach where lungs are distributed on the basis of both medical urgency (i.e. risk of death without a transplant) and net transplant benefit (i.e. the anticipated survival prolongation enabled by transplantation). Scores are calculated from survival models that capture projected 1-yr survivals with and without transplantation. The higher the score, the greater the likelihood patients will succumb to their disease without transplant and the greater the likelihood they will thrive post-transplant [61].

The implementation of the LAS system has significantly shifted the landscape of patients who receive transplants [62]. This has been closely evaluated in the more commonly transplanted conditions, such as chronic obstructive pulmonary disease, IPF, cystic fibrosis and $\mathrm{PH}$. The influence of this change has not been systematically examined in sarcoidosis. Nonetheless, a UNOS data query for the 2.5-yr period after the implementation of the LAS system (May 2005 to December 2007), suggests that there has been a change in the severity of illness and outcomes on the list of sarcoidosis patients since the implementation of the LAS (S.D. Nathan, personal communication). Although prior data would suggest that sarcoidosis patients are generally sicker at the time of listing for transplantation, the distribution of LAS scores compared to those of IPF patients suggests that the opposite is true (fig. 5). For example, $42 \%$ of the sarcoidosis patients listed for bilateral LTx had relatively low scores of between 30 and 35, as opposed to only $13.4 \%$ of IPF patients. The 6- and 12-month mortality rate of these two cohorts in the absence of transplantation was $1.75 \%$ versus $5.26 \%$ and $3.51 \%$ versus $10.7 \%$ for sarcoidosis and IPF, respectively. These outcomes are noteworthy, especially in lieu of the longer median waiting time for sarcoidosis (390 days) compared with IPF patients (196 days). This difference in outcomes also underscores the imprecise nature of survival prediction models for both sarcoidosis and IPF. This era-dependent prognostic switch could reflect that patients with milder IPF and, possibly, sicker patients with sarcoidosis are less likely to be referred or listed for LTx.

\section{Sarcoidosis-specific issues: implications for transplantation}

Sarcoidosis as a multisystem disease

Sarcoidosis is a multisystem disease and, therefore, extrapulmonary manifestations need to be taken into consideration during the workup for transplantation. While the thorax is the most common site of disease, cutaneous, ocular, neurological and cardiac sarcoidosis occur in $25-30 \%$ of patients [63]. Indeed, although the characteristic non-caseating granulomas have been reported in virtually every organ system, their presence does not necessarily imply current or future organ dysfunction, and in many cases, is an incidental finding. Therefore, the decision to perform LTx must be individualised

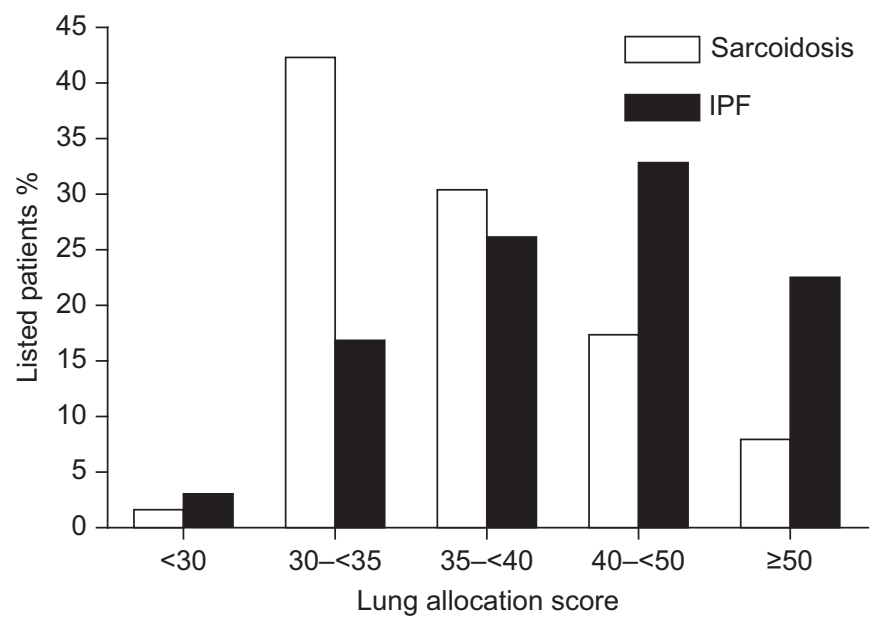

FIGURE 5. Distribution of lung allocation score of patients with sarcoidosis and idiopathic pulmonary fibrosis (IPF) (United Network for Organ Sharing (UNOS) query, 2008). UNOS data from May 4, 2005 to December 31, 2007. n=1,339 IPF patient registrants; $n=184$ sarcoidosis registrants. 
based on the severity of the lung disease and the pathophysiological consequences of any extrapulmonary manifestations.

Cardiac sarcoidosis may potentially have the greatest implications for LTx candidacy since it may portend a poor prognosis [29]. Evidence of cardiac granulomas has been reported in up to $25 \%$ of autopsy specimens in the USA and in $50 \%$ of patients in Japan $[63,64]$. Clinically apparent disease occurs in only $\sim 5 \%$ of patients in the USA and up to $20 \%$ of patients in Japan [65].

There is no consensus approach to screen for cardiac sarcoidosis. However, there are a number of studies that have examined various modalities, such as positron emission tomographic scanning, gallium scintigraphy and cardiac magnetic resonance imaging (MRI) [66]. Although there is use for these modalities in the detection of occult sarcoidosis, the ultimate decision of whether this impacts their lung transplant candidacy depends on the cardiac pathophysiological manifestations of the disease process. For the same reason, documentation of the presence or absence of granulomas is immaterial. Indeed, it is also possible that those patients with cardiac manifestations, especially diastolic dysfunction, are thus predisposed by other comorbidities rather than the sarcoidosis itself [30]. Cardiac sarcoidosis can affect any part of the heart and conduction system. Granulomas and subsequent fibrosis may induce conduction abnormalities including heart block and ventricular arrhythmias. Other manifestations may also include mitral regurgitation, left ventricular dysfunction, congestive heart failure, ventricular aneurysms, pericarditis, pericardial effusion and cardiac tamponade [29]. Patients may present with syncope, heart failure and sudden death. Therefore, studies that should be obtained as part of a lung transplant evaluation include an ECG, echocardiogram, and left and right heart catheterisations. MRI might also provide useful information in select cases in which the cardiac status warrants additional investigation. For patients who have symptoms of dizziness or syncope, an event monitor might be helpful to discriminate between arrhythmias and $\mathrm{PH}$.

The most important predictor of survival in cardiac sarcoidosis appears to be left ventricular function with an ejection fraction (EF) $<50 \%$ associated with an increased mortality risk [67]. Patients with significant left ventricular dysfunction may be considered for heart-lung transplantation. However, the presence of compromised left ventricular function can represent a transplant conundrum in that the EF might not be low enough to warrant heart transplantation, but could be sufficiently reduced to represent a contra-indication to LTx alone.

\section{Parenchymal complications}

Cavities and mycetomas

Cavitary lesions can be seen in all the stages of sarcoidosis, but are most common in stage III and IV disease, with a reported prevalence on chest radiography of $0.6-1.3 \%$ and on CT image of $2.2 \%$ [68-70]. Most cavitary lesions do not resolve, but spontaneous resolution has been reported in about $10-25 \%$ of patients [70]. They tend to be multiple in most cases and either unilateral or bilateral with an upper and mid-lung zone predilection (figs 1 and 6). The cavities may vary in diameter from 10 to $100 \mathrm{~mm}$ and can be both thin- and thick-walled in nature. Thin-walled cavities are more common in the absence

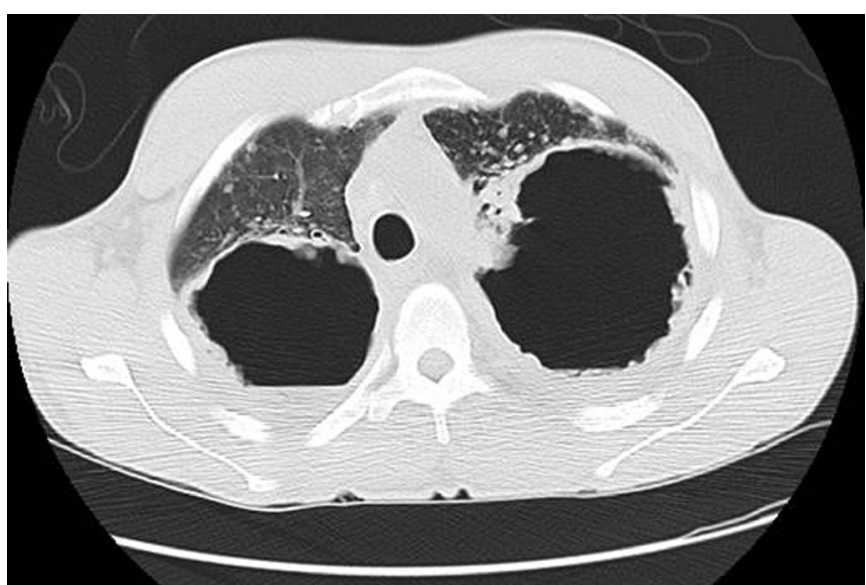

FIGURE 6. Cavities in stage IV sarcoidosis.

of complicating aspergillomas, while in the presence of aspergillomas, thick-walled cavities predominate.

Mycetomas are masses of fungal mycelia that grow in preexisting lung cavities and are therefore most commonly seen in stage III and IV sarcoidosis [71] (fig. 7). Although fungus balls can be caused by many fungi, most are caused by members of the Aspergillus genus [70, 72]. The exact incidence of aspergillomas in sarcoidosis is uncertain, although studies report an incidence of $\sim 2 \%[70,73]$.

The natural history of aspergillomas is variable. Most are stable and do not progress under observation. Some increase in size and $\sim 10 \%$ resolve spontaneously [74]. Data from our centre (Inova Fairfax Hospital) suggest that the presence of aspergillomas does appear to be associated with worse outcomes (fig. 8) [75]. Whether this is a direct result of the aspergilloma or if its presence is a surrogate for disease severity remains uncertain.

Many fungus balls are asymptomatic and are only discovered during routine radiographic surveillance. Some patients present with haemoptysis, which is the most important clinical feature of this complication. It is estimated that $90 \%$ of the patients experience at least one episode of haemoptysis. The magnitude of the haemoptysis ranges from trivial to massive. Haemoptysis has been ascribed to local vascular invasion of the cavity wall by Aspergillus organisms. Collateral vessels from the bronchial arteries and from systemic arteries of the chest wall may augment the blood supply to inflammatory tissue around the cavity, predisposing to serious bleeding $[70-73,76]$. Other potential pathogenic mechanisms have been proposed, including friction of the mobile fungus ball against a hypervascular wall, toxins or enzymes released by the fungus, a type III antibody-antigen reaction, and conversion to chronic necrotising aspergillosis. The source of the bleeding is not always evident, especially in the context of multiple aspergillomas, and the possibility of any haemoptysis being due to other causes, such as tracheobronchitis, is always worth considering. There are a few reports of dissemination to invasive pulmonary aspergillosis, but the risk is generally considered negligible [77]. Indeed, it is likely that it is only those patients who receive immunosuppressive and cytotoxic drugs who are at risk of developing invasive disease [72]. 


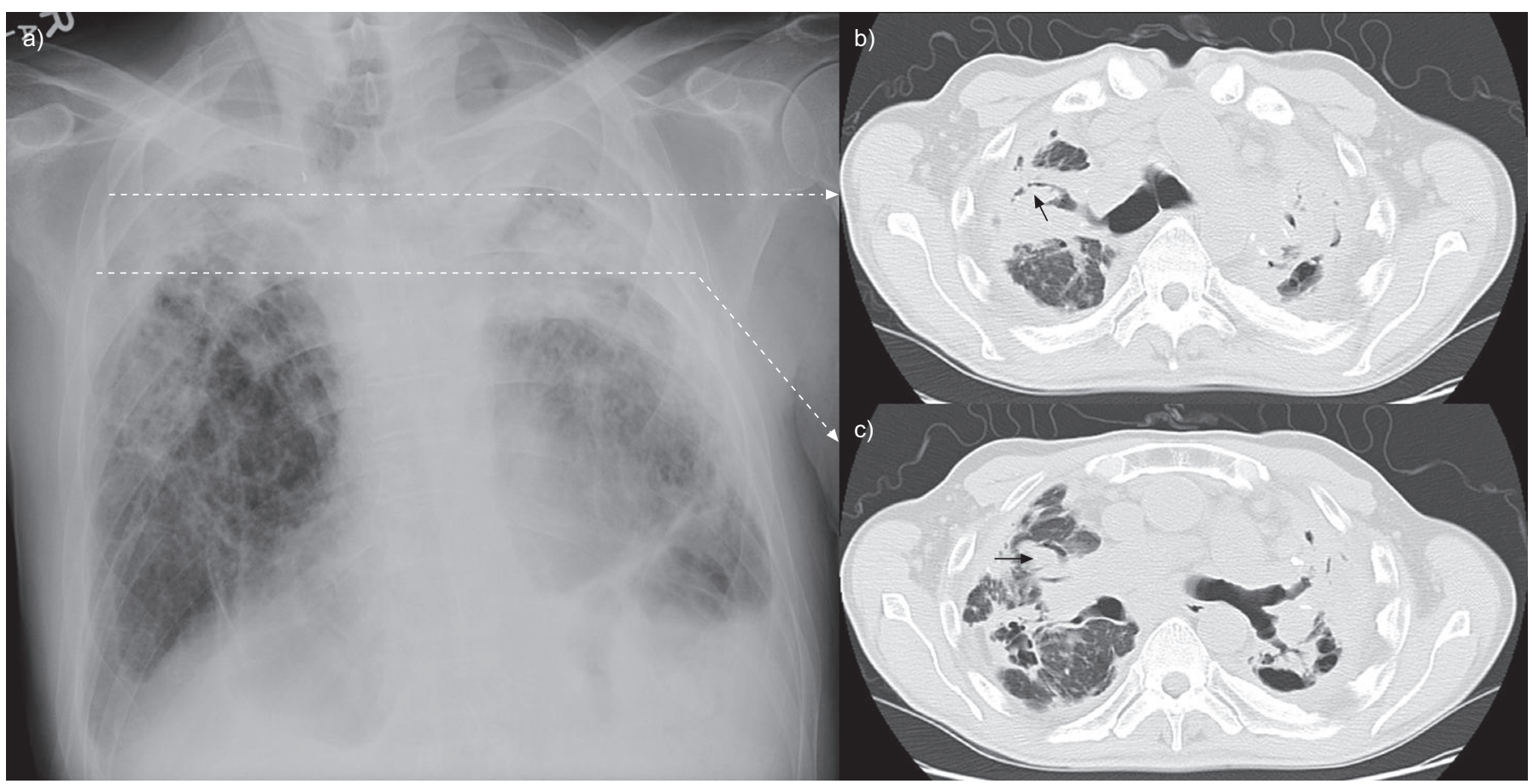

FIGURE 7. a) Chest radiograph and b) computed tomography (CT) images at the corresponding levels. Multiple bilateral mycetomas in stage IV sarcoidosis are shown by the black arrows on the $\mathrm{CT}$ images.

The diagnosis is usually established by the presence of a seemingly mobile mass within a cavity seen on chest radiograph or CT image. Characteristically, the lung cavities containing the aspergilloma have thickened walls [70]. Cultures and serological evaluation may also be helpful, but are not necessary to establish the diagnosis [69, 76]. The organism can usually be cultured from expectorated sputum, while $100 \%$ of patients with an established aspergilloma have serum precipitins against Aspergillus, usually with multiple bands. The occasional negative precipitin test ordinarily occurs in the context of a non-fumigatus Aspergillus species.

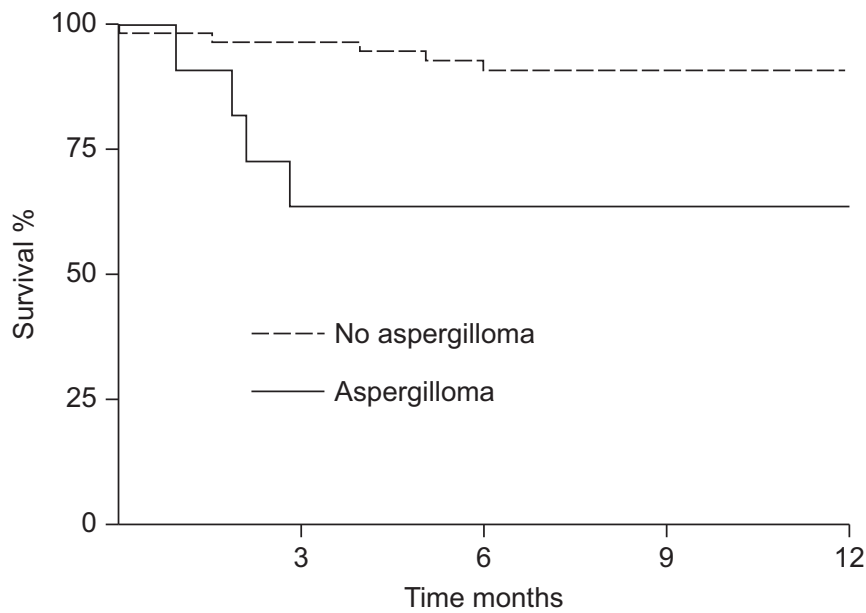

FIGURE 8. Kaplan-Meier survival curves of patients with advanced sarcoidosis stratified by the presence $(n=11)$ or absence $(n=57)$ of aspergillomas. Data from Inova Fairfax Hospital (Falls Church, VA, USA); September, 2006; $p=0.009$.
There is no consensus or guideline for the treatment of sarcoidosis-associated aspergillomas. There are some early reports proposing observation while more recent studies advocate the implementation of therapy [78-80]. Drug therapy of aspergillomas has not been examined in a systematic manner, although the use of itraconazole and more recently voriconazole has been reported $[79,81]$. These may result in symptomatic improvement and even complete resolution of the radiographic findings [82]. The use of intracavitary amphotericin B and voriconazole are also purported treatment approaches [83, 84].

Although resection of the abnormal lung has the potential to be curative, most patients have underlying lung disease that is too advanced to withstand a surgical resection [73, 76, 85, 86]. Additionally, there is the risk of other serious surgical complications, including postoperative infection, bleeding and the development of a bronchopleural fistula [73].

Life-threatening haemoptysis may require emergency surgery, which, until recently, was the only viable treatment option. In medical centres where the technology is available, bronchial artery embolisation under radiographic guidance can be attempted to control the bleeding. Direct instillation of amphotericin B or a saturated solution of potassium iodide into the cavity may also be associated with decreased bleeding and is an alternative option for patients who are poor surgical candidates $[87,88]$.

Currently, the presence of a mycetoma is considered a relative contra-indication for transplantation. Theoretically, there may be an increased risk for seeding the thoracic cavity during explantation, especially if there are cavities that abut the pleura. Additionally, a peripherally located aspergilloma and 

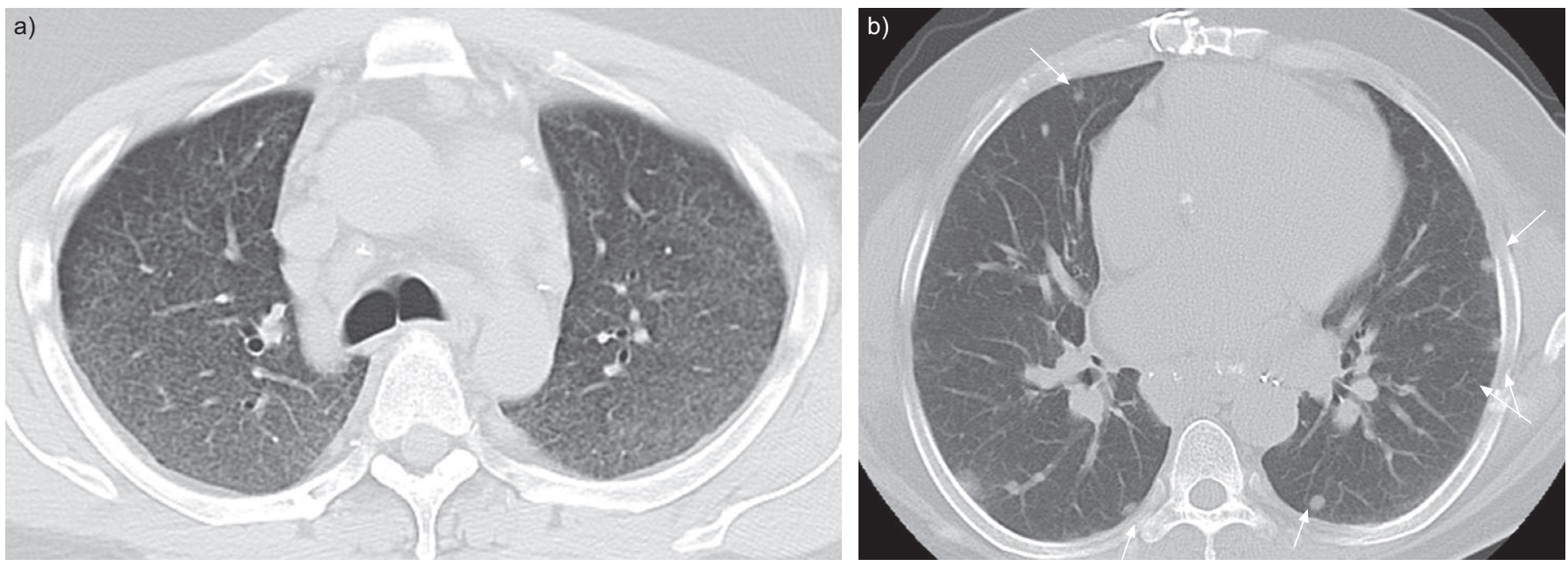

FIGURE 9. Sarcoidosis recurrence post-bilateral lung transplantation in two patients a) demonstrating diffuse reticular nodular infiltrates and b) scattered nodules (white arrows). In both cases, the patients were asymptomatic and transbronchial biopsies demonstrated non-caseating granulomas.

the associated pericavitary inflammatory response can promote pleural thickening, which may complicate the explant part of the procedure. A tedious resection may be associated with a greater propensity for pleural bleeding, especially in those patients who require cardiopulmonary bypass. A complicated surgery may also result in an unduly prolonged cold ischaemic time and increase the risk of primary graft dysfunction (PGD) [89].

The impact of pre-transplant aspergillomas on post-transplant outcomes has not been systematically studied. One small study reported results of nine patients with mycetomas with various underlying diseases, six of whom had sarcoidosis [90]. All six received a bilateral lung transplant and five survived the transplant. Outcomes of the group were significantly worse, with a median survival of only 16 months compared with 56.7 months for other transplant recipients. Although the number of sarcoidosis patients was too small for any meaningful comparison, the authors suggested that aggressive pre-transplant antifungal prophylaxis may impact survival favourably by decreasing the burden of fungal organisms. It is also recommended that the presence of mycetomas be considered as a form of suppurative disease that mandates a bilateral procedure.

\section{Bronchiectasis}

Bronchiectasis is commonly seen in conjunction with radiographic stage IV disease. It is felt to result from mechanical stretch of the airways due to parenchymal fibrosis [91]. Traction bronchiectasis becomes evident as parenchymal disease progresses and has been reported in up to $40 \%$ of patients with the fibrotic stages of sarcoidosis $[92,93]$. Localised bronchiectasis of the right middle lobe caused by obstructing sarcoidosis granuloma has also been described [94].

Traction bronchiectasis and bronchial distortion seldom cause bronchiectatic symptoms [91]. Nonetheless, those patients who do manifest with a chronic productive cough should be considered to have suppurative lung disease. It seems reasonable to extrapolate management strategies from the cystic fibrosis literature, since there are no studies in sarcoidosis-related bronchiectasis, and it is unlikely that such studies will ever be performed. Sputum culture to determine the nature and sensitivity of colonising organisms with consideration of therapy based on these is, therefore, prudent. Sarcoidosis with clinical bronchiectasis is an indication for double LTx, since a single lung will place the allograft at risk of infection from the residual native side [95]. Indeed, a higher proportion of bilateral versus single transplants have been performed for sarcoidosis $(2.9 \%$ versus $2.1 \%$ ) [57]. This bias towards the bilateral procedure is likely predicated by additional factors, including patient age and the presence of underlying $\mathrm{PH}$.

\section{Transplant operative considerations}

Sarcoidosis represents one of the more challenging disease processes for transplant surgeons. Not only is there a heightened propensity for pleural thickening and adhesions, but bulky hilar adenopathy and perihilar fibrosis may also result in a difficult surgery. Furthermore, many of these patients have complicating $\mathrm{PH}$ and refractory hypoxaemia that render the surgery difficult to complete once the patient is off cardiopulmonary bypass. This heightens any bleeding predisposition that may result from an extensive native lung resection. The presence of cavities with aspergillomas in the proximity of the resection always carries the added risk of contamination of the pleural space. In such situations, it is the policy at our institution to irrigate the pleural space with amphotericin B-enriched solution after implantation. If there is documented contamination during the surgery, then this irrigation is continued for the first $24 \mathrm{~h}$ post-operatively.

\section{Post-transplant outcomes}

Post-transplant survival in sarcoidosis is equivalent to that of other lung diseases. Specifically, the most recent ISHLT report attests to 1-, 3-, 5- and 10-yr survivals of 72.2, 56.8, 50.6 and $31.1 \%$, respectively [57]. However, during the first year, sarcoidosis patients have a high mortality, which is second only to those patients with idiopathic PAH.

Short-term outcomes were examined in a retrospective UNOS analysis of all sarcoidosis patients who received lung transplants 
between 1995 and 2000 [96]. The study confirmed that only a minority of transplants were performed for this indication $(2.8 \%)$ and that such recipients in the USA were more likely to be African-American, female and younger. They were also more likely to receive double LTx and heart-lung transplant. 30-day survival rates for the sarcoidosis versus non-sarcoidosis patients were $83 \%$ and $91 \%$, suggesting an almost two-fold unadjusted mortality risk in the sarcoidosis cohort. Multivariate analysis determined that the strongest risk factors for increased short-term mortality included the need for combined heartlung transplant as well as donor and recipient race. Specifically, African-American patients were nearly 50\% more likely to die during the initial post-operative period. This difference persisted after excluding heart-lung recipients and controlling for recipient-donor racial mismatch. Finally, the most common cause of death at 30 days after transplant was PGD, whereas infection was the most common culprit among other lung transplant recipients [96]. One might speculate that the greater early mortality due to PGD could be related to a more complicated surgical procedure in many of these cases. Despite a greater risk of death during the first year, sarcoidosis patients seem to achieve long-term survival rates equivalent to other disease types.

Most theories of the aetiology of sarcoidosis invoke either an infectious or immunological source, either of which could impact the post-transplantation course. With regards to these patients' immunologic profiles, several studies have examined the incidence of acute and chronic rejection in this population and found no difference $[97,98]$. There have, however, been many reports of sarcoidosis recurrence in the allograft, with an estimated incidence as high as $66 \%$ [99-101]. The non-caseating granulomas evident on transbronchial lung biopsy specimens usually represent a histopathological curiosity, occasionally accompanied by radiographic abnormalities, but rarely resulting in physiological impairment or symptoms (fig. 9). Nonetheless, there have been isolated case reports of clinically significant recurrence post-transplantation, that usually respond favourably to increased steroid therapy [99-101].

\section{Conclusion}

Although a minority of sarcoidosis patients progress to advanced stages of their disease, respiratory failure does remain a major cause of morbidity and mortality. A high index of suspicion should be held for underlying $\mathrm{PH}$ in all sarcoidosis patients with advanced disease or symptoms that appear disproportionate to the extent of the underlying parenchymal lung disease. A comprehensive workup of $\mathrm{PH}$ should always be considered, as there might be other treatable contributory comorbidities. Management of $\mathrm{PH}$ and other sequelae of advanced disease, including bronchiectasis and aspergillomas, may improve patients' quality of life, possibly improve survival and hopefully forestall the need for transplantation. LTx is a viable, potentially life-saving therapeutic option for select patients with advanced sarcoidosis and may be an underused resource for this population. As with all forms of advanced lung disease, early referral for transplant consideration should always be encouraged.

\section{STATEMENT OF INTEREST}

Statements of interest for both authors can be found at www.erj. ersjournals.com/site/misc/statements.xhtml

\section{REFERENCES}

1 Baughman RP, Teirstein AS, Judson MA, et al. Clinical characteristics of patients in a case control study of sarcoidosis. Am J Respir Crit Care Med 2001; 164: 1885-1889.

2 Rybicki BA, Major M, Popovich J Jr, et al. Racial differences in sarcoidosis incidence: a five year study in a health maintenance organization. Am J Epidemiol 1997; 145: 234-241.

3 Iwai K, Sekiguti M, Hosoda Y, et al. Racial differences in cardiac sarcoidosis incidence observed at autopsy. Sarcoidosis 1994; 11: 248-251.

4 Sulica R, Teirstein AS, Kakarla S, et al. Distinctive clinical, radiographic and functional characteristics of patients with sarcoidosis-related pulmonary hypertension. Chest 2005; 128: 1483-1489.

5 Handa T, Nagai S, Miki S, et al. Incidence of pulmonary hypertension and its clinical relevance in patients with sarcoidosis. Chest 2006; 129: 1246-1252.

6 Gluskowski J, Hawrylkiewicz I, Zych D, et al. Pulmonary haemodynamics at rest and during exercise in patients with sarcoidosis. Respiration 1984; 46: 26-32.

7 Baughman RP, Engel PJ, Meyer CA, et al. Pulmonary hypertension in sarcoidosis. Sarcoidosis Vasc Diffuse Lung Dis 2006; 23: 108-116.

8 Shorr AF, Helman DL, Davies DB, et al. Pulmonary hypertension in advanced sarcoidosis: epidemiology and clinical characteristics. Eur Respir J 2005; 25: 783-788.

9 Simmoneau G, Robbins I, Beghetti M, et al. Updated clinical classification of pulmonary hypertension. JACC 2009; 54: S43-S54.

10 Baughman RP. Pulmonary hypertension associated with sarcoidosis. Arthritis Res Ther 2007; 9: S8.

11 Nunes H, Humbert M, Capron F, et al. Pulmonary hypertension associated with sarcoidosis: mechanisms, haemodynamics and prognosis. Thorax 2006; 61: 68-74.

12 Takemura T, Matsui Y, Saiki S, et al. Pulmonary vascular involvement in sarcoidosis: a report of 40 autopsy cases. Hum Pathol 1992; 23: 1216-1223.

13 Corte T, Wells AU, Nicholson AG, et al. Pulmonary hypertension in sarcoidosis: a review. Respirology 2011; 16: 69-77.

14 Damuth TE, Biwer JS, Cho K, et al. Major pulmonary artery stenosis causing pulmonary hypertension in sarcoidosis. Chest 1980; 78: 888-891.

15 Hiffstein V, Ranganathan N, Mullen JBM, et al. Sarcoidosis stimulating pulmonary veno-occlusive disease. Am Rev Respir Dis 1986; 134: 809-811.

16 Portier F, Lerebourg-Pigeonnaiere G, Thiberville L, et al. Sarcoidosis simulating pulmonary veno-occlusive disease. Rev Mal Respir 1991; 8: 101-102.

17 Toonkel RL, Borczuk AC, Pearson GD, et al. Sarcoidosisassociated fibrosing mediastinitis with resultant pulmonary hypertension: a case report and review of literature. Respiration 2009; 79: 341-345.

18 Smith LJ, Lawrence JB, Katzenstein AL. Vascular sarcoidosis: a rare case report of pulmonary hypertension. Am J Med Sci 1983; 285: 38-44.

19 Rosen Y, Moon S, Huang CT, et al. Granulomatous pulmonary angiitis in sarcoidosis. Arch Pathol Lab Med 1977; 101: 170-174.

20 Thannickal VJ, Toews GB, White ES, et al. Mechanisms of pulmonary fibrosis. Annu Rev Med 2004; 55: 395-417.

21 Mahapatra S, Nishimura RA, Sorajja P, et al. Relationship of pulmonary arterial capacitance and mortality in idiopathic pulmonary arterial hypertension. J Am Coll Cardiol 2006; 47: 799-803.

22 Galie N, Manes A, Branzi A. The endothelin system in pulmonary arterial hypertension. Cardiovasc Res 2004; 61: 227-237. 
23 Terashita K, Kato S, Sata M, et al. Increased endothelin-1 levels of BAL fluid in patients with pulmonary sarcoidosis. Respirology 2006; 11: 145-151.

24 Letizia C, Danese A, Reale MG, et al. Plasma levbels of endothelin-1 increase in patients with sarcoidosis and fall after disease remission. Panminerva Med 2001; 43: 257-261.

25 Sutendra G, Dromparis P, Bonnet S, et al. Pyruvate dehydrogenase inhibition by the inflammatory cytokine TNF $\alpha$ contributes to the pathogenesis of pulmonary aterial hypertension. J Mol Med 2011; 89: 771-783.

26 Chen ES, Moller DR. Sarcoidosis - scientific progress and clinical challenges. Nature Rev Rheumatol 2011; 7: 457-467.

27 Preston IR, Klinger JR, Landzberg MJ, et al. Vasoresponsivness of sarcoid-associated pulmonary hypertension. Chest 2001; 120: 866-872.

28 Barst RJ, Ratner SJ. Sarcoidosis and Reactive Pulmonary Hypertension. Arch Intern Med 1985; 145: 2112-2114.

29 Bargout R, Kelly RF. Sarcoid heart disease: clinical course and treatment. Int J Cardiology 2004; 97: 173-182.

30 Baughman RP, Engel PJ, Taylor L, et al. Survival in sarcoidosis associated pulmonary hypertension: the importance of hemodynamic evaluation. Chest 2010; 138: 1078-1085.

31 Salazaar A, Mana J, Sala J, et al. Combined portal and pulmonary hypertension in sarcoidosis. Respiration 1994; 61: 517-520.

32 Turner GA, Lower EE, Corser BC, et al. Sleep apnea in sarcoidosis. Sarcoidosis Vasc Diffuse Lung Dis 1997; 14: 61-64.

33 Swigris JJ, Olson AL, Huie TJ, et al. Increased risk of pulmonary embolism among US decedents with sarcoidosis from 1988 to 2007. Chest 2011; 140: 1261-1266.

34 Crawshaw AP, Wotton CJ, Yeates DG, et al. Evidence for association between sarcoidosis and pulmonary embolism from 35-year record linkage study. Thorax 2011; 66: 447-448.

35 Shorr AF, Davies DB, Nathan SD. Predicting mortality in patients with sarcoidosis awaiting lung transplantation. Chest 2003; 124: 922-928.

36 Arcasoy SM, Christie JD, Pochettino A, et al. Characteristics and outcomes of patients with sarcoidosis listed for lung transplantation. Chest 2001; 120: 873-880.

37 Diaz-Guzman E, Farver C, Parambil J, et al. Pulmonary hypertension caused by sarcoidosis. Clin Chest Med 2008; 29: 549-566.

38 Leuchte $\mathrm{HH}$, Baumgartner RA, Nounou ME, et al. Brain natriuretic peptide is a prognostic parameter in chronic lung diseases. Am J Respir Crit Care Med 2006; 173: 744-750.

39 Corte TJ, Wort SJ, Gatzoulis MA, et al. Elevated brain natriuretic peptide predicts mortality in interstitial lung disease. Eur Respir J 2010; 36: 819-825.

40 Handa T, Nagai S, Ueda S, et al. Significance of plasma NTpreBNP levels as a biomarker in the assessment of cardiac involvement and pulmonary hypertension in patients with sarcoidosis. Sarcoidosis Vasc Diffuce Lung Dis 2010; 27: 27-35.

41 Bourbonnais JM, Samavati L. Clinical predictors of pulmonary hypertension in sarcoidosis. Eur Respir J 2008; 32: 296-302.

42 Baughman RP, Sparkman BK, Lower EE. Six minute walk test and health status assessment in sarcoidosis. Chest 2007; 132: 207-213.

43 Palmero V, Sulica R. Sarcoidosis-associated pulmonary hypertension: assessment and management. Semin Respir Crit Care Med 2010; 31: 494-500.

44 Alhamad EH, Ahmad Shaik S, Idrees MM, et al. Outcome measures of the 6 minute walk test: relationships with physiologic and computed tomography findings in patients with sarcoidosis. BMC Pulm Med 2010; 10: 42-49.

45 Arcasoy SM, Christie JD, Ferrari VA, et al. Echocardiographic assessment of pulmonary hypertension in patients with advanced lung disease. Am J Respir Crit Care Med 2003; 167: 735-740.
46 Rodman DM, Lindenfeld J. Successful treatment of sarcoidosisassociated pulmonary hypertension with corticosteroids. Chest 1990; 97: 500-502.

47 Davies J, Nellen M, Goodwin JF. Reversible pulmonary hypertension in sarcoidosis. Postgrad Med J 1982; 58: 282-285.

48 Gluskowski J, Hawrylkiewicz I, Zych D, et al. Effects of corticosteroid treatment on pulmonary haemodynamics in patients with sarcoidosis. Eur Respir J 1990; 3: 403-407.

49 Diaz-Guzman E, Farver C, Parambil J, et al. Pulmonary hypertension caused by sarcoidosis. Clin Chest Med 2008; 29: 549-571.

50 Baughman RP, Judson MA, Lower EE, et al. Inhaled iloprost for sarcoidosis associated pulmonary hypertension. Sarcoidosis Vasc Diffuse Lung Dis 2009; 26: 110-120.

51 Fisher KA, Serlin DM, Wilson KC, et al. Sarcoidosis-associated pulmonary hypertension: outcome with long-term epoprostenol treatment. Chest 2006; 130: 1481-1488.

52 Barnett CF, Bonura EJ, Nathan SD, et al. Treatment of sarcoidosis-associated pulmonary hypertension. A two-center experience. Chest 2009; 135: 1455-1461.

53 Milman N, Burton CM, Iversen M, et al. Pulmonary hypertension in end-stage pulmonary sarcoidosis: therapeutic effect of sildenafil? J Heart Lung Transplant 2008; 75: 329-334.

54 Culver DA, Minai OA, Chapman JT, et al. Treatment of pulmonary hypertension in sarcoidosis. Proc Am Thoracic Soc 2005; 2: A862.

55 Judson MA, Ford HJ, Donohue JF, et al. Ambrisentan for sarcoidosis associated pulmonary hypertension. Am I Respir Crit Care 2010; 181: A2368.

56 Baughman RP. Double Blind, Randomized Trial of Bosentan for Sarcoidosis Associated Pulmonary Hypertension. http://clinicaltrials.gov/ct2/show/NCT00581607 Date last accessed: May 10, 2011. Date last updated: November 2, 2011.

57 Hertz MI, Aurora P, Christie JD, et al. Scientific Registry of the International Society for Heart and Lung Transplantation: introduction to the 2010 Annual Reports. J Heart Lung Transplant 2010; 29: 1083-1141.

58 Baughman RP, Winger DB, Bowen EH, et al. Predicting respiratory failure in sarcoidosis patients. Sarcoidosis Vasc Diffuse Lung Dis 1997; 14: 154-158.

59 Shorr AF, Davies DD, Nathan SD. Outcomes for patients with sacroidosis awaiting lung transplantation. Chest 2002; 122: 233-238.

60 Orens JB, Estenne M, Arcasoy S, et al. International guidelines for the selection of lung transplant candidates: 2006 update - a consensus report from the pulmonary scientific council of the International Society for Heart and Lung Transplantation. J Heart Lung Transplant 2006; 25: 745-755.

61 Egan TM, Murray S, Bustami RT, et al. Development of the new allocation system in the United States. Am J Transplant 2006; 6: 1212-1227.

62 Chen H, Shiboski SC, Golden JA, et al. Impact of the lung allocation score on lung transplantation for pulmonary arterial hypertension. Am J Respir Crit Care Med 2009; 180: 468-474.

63 Iannuzzi MC, Fontana JR. Sarcoidosis: clinical presentation, immunopathogenesis and therapeutics. JAMA 2011; 305: 391-399.

64 Silverman KJ, Hutchins GM, Bulkley BH. Cardiac sarcoid: a clinicopathologic study of 84 unselected patients with systemic sarcoidosis. Circulation 1978; 58: 1204-1211.

65 Mehta D, Lubitz SA, Frankel Z, et al. Cardiac involvement in patients with sarcoidosis: diagnostic and prognostic value of outpatient testing. Chest 2008; 35: 933-941.

66 Patel MR, Cawley PJ, Heitner JF, et al. Detection of myocardial damage in patients with sarcoidosis. Circulation 2009; 120 1969-1977. 
67 Yazake $Y$, Isobe M, Hiroe M, et al. Prognostic determinants of long-term survival in Japanese patients with cardiac sarcoidosis treated with prednisone. Am J Cardiol 2001; 88: 1006-1010.

68 Freundlich IM, Libshitz HI, Glassman LM, et al. Sarcoidosis. Typical and atypical thoracic manisfestations. Clin Radiol 1970 21: $376-383$

69 Wollschlager C, Khan F. Aspergillomas complicating sarcoidosis: a prospective study in 100 patients. Chest 1984; 86: 585-588.

70 Hours S, Nunes H, Kambouchner M, et al. Pulmonary cavitary sarcoidosis. Medicine 2008; 87: 142-151.

71 Gorske K, Fleming RJ. Mycetoma formation in cavitary sarcoidosis. Radiology 1970; 95: 279-285.

72 Dar MA, Ahmad M, Weinstein AJ, et al. Thoracic aspergillosis (Part I): overview and aspergilloma. Cleve Clin Q 1984; 51: 615-630.

73 Pena T, Soubani AO, Samavati L. Aspergillus lung disease in patients with sarcoidosis: a case series and review of the literature. Lung 2011; 189: 167-172.

74 Hammerman KJ, Christianson CS, Huntington I. Spontaneous lysis of aspergilloma. Chest 1973; 64: 697-699.

75 Nathan SD, Saleeb PG, Saft H, et al. Prevalence and impact of aspergillomas in patients with advanced sarcoidosis. Am J Respir Crit Care Med 2007; 175: A361.

76 Israel HL, Ostrow A. Sarcoidosis and aspergilloma. Am J Med 1969; 47: 243-250.

77 Waldhorn RE, Tsou E, Kerwin DM. Invasive pulmonary aspergillosis associated with aspergilloma in sarcoidosis. South Med J 1983; 76: 251-253.

78 Kaplan J, Johnson Johns C. Mycetomas in pulmonary sarcoidosis: non-surgical management. Johns Hopkins Med J 1979; 145 157-161.

79 Stevens DA, Kan VL, Judson MA, et al. Practice guidelines for disease caused by aspergillus. Infectious Dis Soc of Amer 2000; 30: 696-709.

80 Sharma OP, Chwogule R. Many faces of pulmonary aspergillosis. Eur Respir J 1998; 12: 705-715.

81 Dannaouli E, Garcia-Hermoso D, Naccache JM, et al. Use of voriconazole in a patient with aspergilloma caused by an itraconazole-resistance strain of Aspergillus fumigatus. J Med Microbiol 2006; 55: 1457-1459.

82 De Beule K, De Doncker P, Cauwenbergh G, et al. The treatment of aspergillosis and aspergilloma with itraconazole, clinical results of an open international study (1982-1987). Mycoses 1988; 31: 476-485.

83 Kravitz JN, Bullington WM, Schabel S, et al. Intracavitary amphotericin B for pulmonary aspergilloma complicated by serious hemoptysis in fibrocystic sarcoidosis. Am J Respir Crit Care 2010; 181: A2951.

84 Kravitz JN, Steed LL, Judson MA. Intracavitary voriconazole for the treatment of hemoptysis complicating Pseudallescheria angusta pulmonary mycetomas in fibrocystic sarcoidosis. Med Mycol 2011; 49: 198-201.

85 Lencher GS, Atkinson GW. Sarcoidosis and aspergilloma. The role of surgery. Chest 1982; 82: 430-432.

86 Gueraa M, Santos N, Miranda J, et al. Surgical management of pulmonary aspergilloma. Rev Port Cir Cardiothorac Vasc 2008; 15: 135-138.

87 Jackson M, Flower CD, Shneerson JM. Treatment of symtpomatic pulmonary aspergillomas with intracavitary instillation of amphotericin B through an indwelling catheter. Thorax 1993; 48: 928-930.

88 Rumbak M, Kohler G, Eastridge C, et al. Topical treatment of life threatening haemoptysis from aspergillomas. Thorax 1996; 51: 253-255.

89 Judson MA. Lung transplantation for pulmonary sarcoidosis Eur Respir J 1998; 11: 738-744.

90 Hadjiliadis D, Sporn TA, Perfect JR, et al. Outcome of lung transplantation in patients with mycetomas. Chest 2002; 121: 128-134.

91 Polychronopoulos VS, Prakash UB. Airway involvement in sarcoidosis. Chest 2009; 136: 1371-1380.

92 Akira M, Kozuka T, Inoue $\mathrm{Y}$, et al. Long-term follow-up CT scan evaluation in patients with pulmonary sarcoidosis. Chest 2005; 127: 185-191.

93 Abehsera M, Valeyre D, Grenier P, et al. Sarcoidosis with pulmonary fibrosis: $\mathrm{CT}$ patterns and correlation with pulmonary function. Am J Roentgenol 2000; 174: 1751-1757.

94 Rockoff SD, Rohatgi PK. Unusual manifestations of thoracic sarcoidosis. Am I Roentgenol 1985; 144: 513-528.

95 Shah L. Lung transplantation in sarcoidosis. Semin Respir Crit Care Med 2007; 28: 134-140.

96 Shorr AF, Helman DL, Davies DB, et al. Sarcoidosis, race and short-term outcomes following lung transplantation. Chest 2004; 125: 990-996.

97 Nunley DR, Hattler B, Keenan RJ, et al. Lung transplantation for end-stage pulmonary sarcoidosis. Sarcoidosis Vasc Diffuse Lung Dis 1999; 16: 93-100.

98 Wille KM, Gaggar A, Hajari AS, et al. Bronchiolitis obliterans syndrome and survival following lung transplantation for patients with sarcoidosis. Sarcoidosis Vasc Diffuse Lung Dis 2008; 25: $117-124$

99 Milman N, Andersen CD, Burton CM, et al. Recurrent sarcoid granulomas in a transplanted lung derive from recipient immune cells. Eur Respir J 2005; 26: 549-552.

100 Johnson BA, Duncan SR, Ohori NP, et al. Recurrence of sarcoidosis in pulmonary allograft recipients. Am Rev Respir Dis 1993; 148: 1373-1377.

101 Martinez FJ, Orens JB, Deeb M, et al. Recurrence of sarcoidosis following bilateral allogeneic lung transplantation. Chest 1994 106: $1597-1599$. 